ARTICLE

https://doi.org/10.1038/s41467-019-09996-z

\title{
The major secreted protein of the whipworm parasite tethers to matrix and inhibits interleukin-13 function
}

\author{
Allison J. Bancroft ${ }^{1,2,3,4}$, Colin W. Levy ${ }^{5}$, Thomas A. Jowitt ${ }^{2,4}$, Kelly S. Hayes ${ }^{1,2,3,4}$, Seona Thompson ${ }^{1,2,3,4}$, \\ Edward A. Mckenzie ${ }^{5}$, Matthew D. Ball ${ }^{5}$, Eamon Dubaissi ${ }^{1,2,3,4}$, Aidan P. France ${ }^{5}$, Bruno Bellina ${ }^{5}$, \\ Catherine Sharpe ${ }^{1,2,3,4}$, Aleksandr Mironov4, Sheila L. Brown ${ }^{1,3,4,6}$, Peter C. Cook (1) 1,3,4,6, \\ Andrew S. MacDonald (10) 1,3,4,6, David J. Thornton (10) 1,2,3,4 \& Richard K. Grencis 1,2,3,4
}

Infection by soil transmitted parasitic helminths, such as Trichuris spp, are ubiquitous in humans and animals but the mechanisms determining persistence of chronic infections are poorly understood. Here we show that p43, the single most abundant protein in $T$. muris excretions/secretions, is non-immunogenic during infection and has an unusual sequence and structure containing subdomain homology to thrombospondin type 1 and interleukin (IL) -13 receptor $(R) \alpha 2$. Binding of p43 to IL-13, the key effector cytokine responsible for T. muris expulsion, inhibits IL-13 function both in vitro and in vivo. Tethering of p43 to matrix proteoglycans presents a bound source of p43 to facilitate interaction with IL-13, which may underpin chronic intestinal infection. Our results suggest that exploiting the biology of $\mathrm{p} 43$ may open up new approaches to modulating IL-13 function and control of Trichuris infections.

\footnotetext{
${ }^{1}$ Lydia Becker Institute for Immunology and Inflammation, Manchester M13 9PT, UK. ${ }^{2}$ Wellcome Trust Centre for Cell Matrix Research, Manchester M13 9PT, UK. ${ }^{3}$ Division of Infection, Immunity and Respiratory Medicine, Manchester M13 9PT, UK. ${ }^{4}$ School of Biological Sciences, Faculty of Biology, Medicine and Health, Manchester Academic Health Science Centre, University of Manchester, Manchester M13 9PL, UK. ${ }^{5}$ Manchester Institute of Biotechnology, University of Manchester, 3.020 Garside Building, 131 Princess Street, Manchester M1 7DN, UK. ${ }^{6}$ Manchester Collaborative Centre for Inflammation Research, Division of Infection, Immunity and Respiratory Medicine, School of Biological Sciences, Faculty of Biology, Medicine and Health, Manchester Academic Health Science Centre, Core Technology, University of Manchester, 46 Grafton Street, Manchester M13 9NT, UK. Correspondence and requests for materials should be addressed to A.J.B. (email: allison.j.bancroft@manchester.ac.uk) or to R.K.G. (email: Richard.Grencis@manchester.ac.uk)
} 
S oil-transmitted helminths (STHs) are responsible for infections that form part of the World Health Organization defined neglected tropical diseases, and as such present a considerable public health problem currently affecting around 1.9 billion people worldwide ${ }^{1}$. Infection with Trichuris trichiura, commonly known as whipworm (one of the four major STH), currently infects approximately 477 million people ${ }^{1}$. As a member of the prevalent Trichuris genus, these parasites occupy a distinct niche, the epithelial layer of the cecum, and proximal colon of the large intestine ${ }^{2}$, and parasites exist as long-lived, chronic infections. Little is known about how they maintain prolonged survival within the host, although there is remarkable genotypic and phenotypic similarity among Trichuris species ${ }^{3,4}$, regardless of the host, suggesting that common mechanisms underlying chronic infection may operate.

In addition to underpinning the role of interleukin-13 (IL-13)mediated protective immunity to gastrointestinal-dwelling nematode infections, ${ }^{5,6}$ the naturally rodent-infecting species, Trichuris muris, has been successfully used as an experimental model of chronic STH helminth infection ${ }^{7,8}$. Under natural conditions, infection occurs by repeated low-level ingestion of eggs; IL-13-dependent protective immunity is slow to develop and partial at best. Parasite survival, therefore, ultimately depends upon the ability of Trichuris to disrupt effective IL-13-mediated immunity. Understanding how this group of parasites is able to achieve this, is vital to infection control, and potential elimination as current anthelmintic therapy in humans, is rarely completely effective, with $T$. trichiura often being the most persistent human STH following anthelmintic treatment ${ }^{9,10}$.

Here we characterize the structure and function of $\mathrm{p} 43$, the single most abundant protein in secretions from adult T. muris, whipworm. Structural determination by X-ray crystallography reveals potential interaction with glycosaminoglycans and the host cytokine IL-13. Binding studies confirm high-affinity binding to heparan sulfate (HS) and IL-13. Moreover, p43 inhibits IL13 immune function both in vitro and in vivo. The presence of p43 homologs in closely related whipworms, such as T. trichiura, is suggestive of common immunomodulatory function.

\section{Results}

p43 location in the parasite and the host. The excretome/ secretome $(\mathrm{E} / \mathrm{S})$ of parasitic nematodes is extensive and represents a major source of extracellular parasite material that can interact with the host, containing both immunogens and immunomodulatory molecules ${ }^{11}$. The $\mathrm{E} / \mathrm{S}$ of adult T. muris is no less extensive ${ }^{12}$ but is dominated by a single protein that can be visualized by sodium dodecyl sulfate-polyacrylamide gel electrophoresis (SDS-PAGE) resolving at a band of approximately 43 $\mathrm{kDa}$ and was termed p43 (Supplementary Fig. 1a). Multi-angle light scattering of native T. muris $\mathrm{E} / \mathrm{S}$ confirmed the dominance of p43 in E/S as a monomeric protein (Supplementary Fig. 1b), which is encoded for by TMUE_3000012139, a poly-cysteine and histidine-tailed protein gene (Supplementary Fig. $2 a, b)^{3}$. The protein encoded for by this gene has an unknown function, but is the tenth most highly expressed in adult worms ${ }^{3}$, suggesting major investment by the parasite and thus importance in the host/parasite relationship. Real-time polymerase chain reaction (qPCR) confirmed p43 RNA expression in all life cycle stages (Supplementary Fig. 1c). Secretion of p43 was confirmed by culturing adult worms in increasing concentrations of sodium azide (Supplementary Fig. 1d). Western blotting (Fig. 1a) and mass spectrometry (Supplementary Table 1) confirmed the presence of p43 in the secreted mucus from chronically infected mice. It is clearly present in the mucus from the cecum, the parasite niche as opposed to the colon, where parasites are not present after low-dose chronic infection (Fig. 1a, Supplementary Table 1). Accordingly, p43 protein can be readily observed in both the epithelial matrix surrounding the parasite in situ and in the host intestinal lumen (Fig. 1b-d, Supplementary Fig. 3a). The p43 protein is located beneath the cuticle in adult parasites (Fig. 1c, d) and transcription of the $\mathrm{p} 43$ gene and myosin gene is co-located (Fig. 1e, Supplementary Fig. 3b), suggesting muscle origin, and is consistent with the protein residing within or alongside the longitudinal muscle layer of the parasite (Fig. 1f, g). Immunogold electon microscopy confirmed labeling of p43 protein between the muscle cells (Fig. 1f, g, Supplementary Fig. 3c). Taken together with the considerable change in size from L1 to adult (approximately 5000-fold increase in body/muscle volume over a 35-day period), it is clear that adult parasites produce the greatest quantity of p43 of all life cycle stages.

Crystal structure of p43. Sequence-based similarity searches reveal high levels of orthology between $\mathrm{p} 43$ and predicted proteins identified in other Trichuris species and closely related Trichinella species, suggesting that the molecules may be isostructural and therefore perform a common function within this group of parasites (Supplementary Fig. 4). Trichuris muris $\mathrm{p} 43$ comprises 397 amino acids (AA), 36 cysteine residues (9\%), and a histidine-rich C-terminal region (45\% of terminal 29 residues are His). Analyses of the primary sequence reveal an internal repeat with residues $1-180$ and $181-394$ sharing $34 \%$ amino acid sequence identity. To better understand the possible function of $\mathrm{p} 43$, we determined the three-dimensional structure at $1.8 \AA$ using X-ray crystallography, Protein Data Bank (PDB) ID 6QIX.

The protein has mixed $\alpha$ and $\beta$ composition with $16 \beta$-strands and 6 a-helices (Fig. 2a). The crystal structure reveals contiguous electron density for residues 21-368, and no electron density is observed for the histidine-rich C-terminal region. The structure shows that all 36 of the available cysteine residues are involved in the formation of 18 intramolecular disulfide bonds (Supplementary Fig. 5a). In each of the two domain repeats, eight disulfides are conserved, while the bond between C274 and C277 has no equivalent in domain 1 and C131 from domain 1 bonds to C362 of domain 2. The disulfide bonding pattern is unevenly distributed throughout the protein clustering around the $\beta$-sandwich region $(\beta 4-\beta 8$, Fig. 2, Supplementary Fig. 5a). There are three potential N-glycosylation sites predicted at positions 57,174 , and 287 , and the crystal structure shows clear evidence of glycosylation at residues 57 and 287, but not at position 174 (Fig. 2b). In addition to these three $\mathrm{N}$ glycosylation sites, there is a potential site of C-mannosylation with $\mathrm{p} 43$ containing the $\mathrm{W}-\mathrm{x}-\mathrm{x}-\mathrm{W}$ motif associated with such a modification $^{13}$.

Structure-based similarity searches of the PDB reveal no hits in the Dali server ${ }^{14}$, indicating unique overall structure, while ProBis (Protein Binding Sites), a web server for detecting structurally similar binding sites in proteins ${ }^{15}$, highlights residues (21-25 and 77-104) as having significant similarity to thrombospondin type 1 repeat protein (TSP-1) displaying the characteristic antiparallel three-stranded $\beta$-sheet with a disrupted A strand (Fig. 2c, Supplementary Fig. 5b). The two top hits from ProBis were for micronemal protein 2 from Toxoplasma gondii, an adhesin involved in parasite binding to a matrix prior to cell invasion ${ }^{16,17}$, and human IL-13R a2, a regulatory receptor that controls IL-13 activity $^{18}$. The regions of similarity for each are restricted to specific residues residing within the TSP-1 domains, providing intruiging possibilities for potential roles of $p 43$. Surface representation of $\mathrm{p} 43$ by electrostatic surface potential indicates a negatively charged region, suggestive of a possible binding cleft between the two domain repeats (Fig. $2 \mathrm{~d}$ ). 

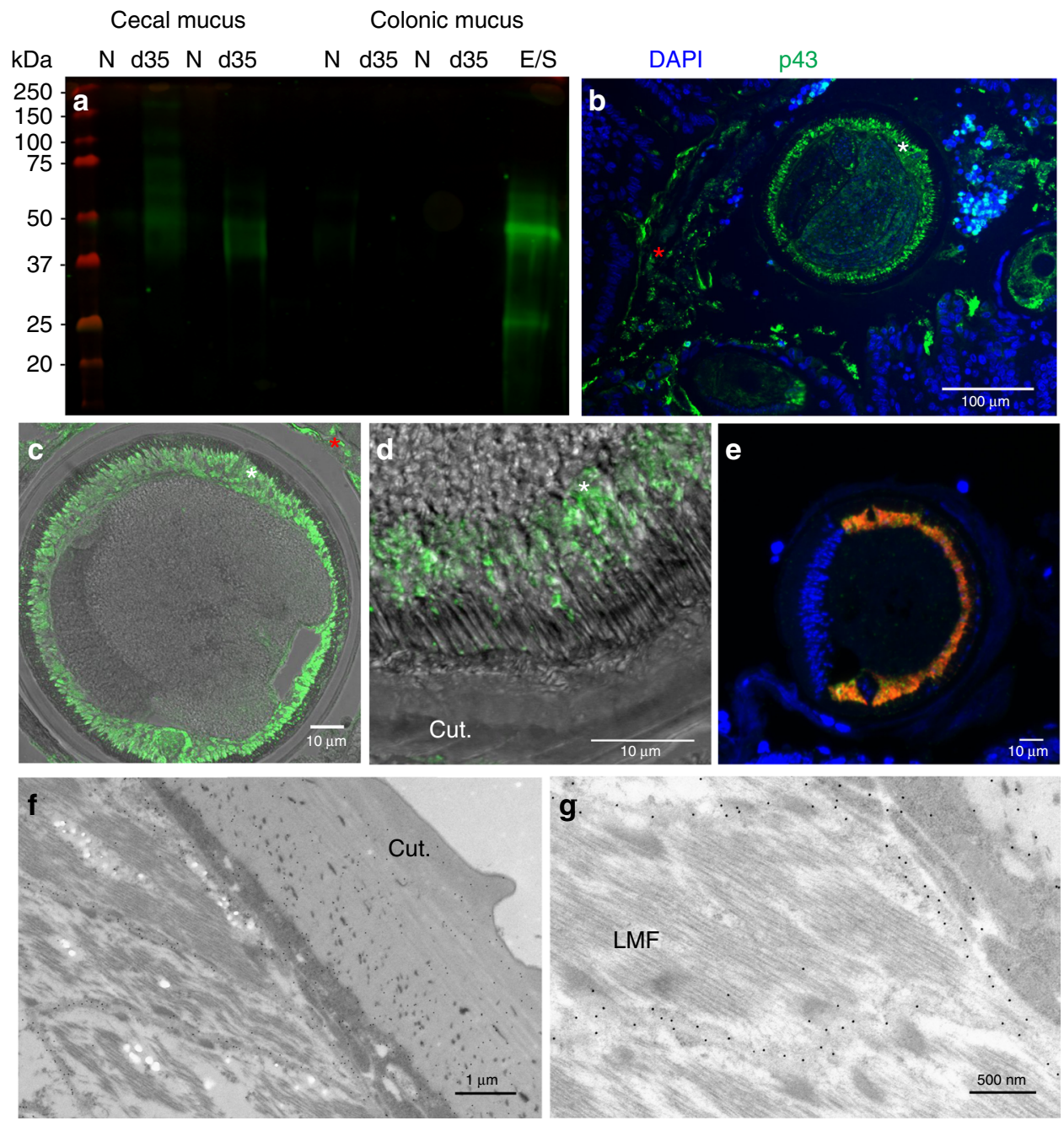

Fig. 1 p43 is associated with the longitudinal muscle of the parasite and the intestinal mucus and the surrounding epithelial matrix of the host. a Western blot of cecal and colonic mucus samples from naive (N), Trichuris muris-infected (d35) mice, and T. muris whole excretome/secretome (E/S) probed with anti-p43 antibody. b Cecal sections from infected mice stained with anti-p43 and 4',6-diamidino-2-phenylindole, dihydrochloride (DAPI) (merged), demonstrating staining within the worm (white asterisk) and extracellularly within the host intestinal lumen (red asterisk). c, d Transverse section of a worm taken from cecal sections from infected mice stained with anti-p43. d p43 staining within the worm (merged with bright field). e Transverse section of an adult T. muris hybridized with a p43 Cy5 probe (red) and myosin fluorescein isothiocyanate (FITC) probe (green); a merged image is shown, counterstained with DAPI. $\mathbf{f}, \mathbf{g}$ Electron micrograph of adult T. muris stained with anti-p43 and colloidal gold particle-conjugated secondary antibodies. (Cut.= cuticle; $L M F=$ longitudinal muscle fibers; white asterisk $=$ within the worm; red asterisk $=$ within the host intestinal lumen)

p43 binds to IL-13 and glycosaminoglycans. As protective immunity to T. muris is dependent on IL-13 function in the intestine, we reasoned that p43 may bind IL-13 and serve as an immunomodulatory molecule. In silico docking of IL-13 binding to 443 is shown in Supplementary Fig. 6. p43 was shown to bind IL-13 directly by microscale thermophoresis (MST) with an equilibrium-binding constant $K_{\mathrm{D}}$ in the order of $420 \pm 120 \mathrm{nM}$ (Fig. 3a). Native mass spectrometry and collision-induced dissociation (CID) experiments showed p43-bound IL-13 with a 1:1 stoichiometry (Fig. 3b) and confirmed that p43 was a flexible molecule with the potential for conformational change upon activation (Supplementary Fig. 7). As predicted by thrombospondin type one domain (TSR-1) homology, p43 was also shown to bind readily to glycosoaminoglycans via enzyme-linked immunosorbent assay (ELISA) (Supplementary Fig. 8) and this was confirmed for HS via surface plasmon resonance (SPR), with an affinity in the region of $10 \mathrm{nM}$ (Fig. 3c). Moreover, p43/HS binding was highly dependent upon the presence of zinc (Fig. 3d). Addition of IL-13 to p43 bound to HS using a competitive SPR method, uncoupled the p43 from HS (Fig. 3e), raising the possibility that the extracellular matrix may present $\mathrm{p} 43$ in a manner receptive to subsequent binding to IL-13. Taken together, the data indicate that p43 may interfere with the biological function of IL13. To test this in vitro, peritoneally derived exudate cells (PECs) were incubated with IL-13 to stimulate the production of resistinlike molecule- $\alpha$ (RELM- $\alpha$ ) in the presence or absence of p43. p43 significantly inhibited the induction of RELM- $\alpha$ induced by IL-13 but not IL-4 (Fig. 3f, g), showing that p43 inhibited IL-13 function. p43 was also shown in vivo to significantly inhibit the induction of RELM- $a^{+}$lung interstitial macrophages ${ }^{19-22}$ following administration of IL-13 to the respiratory tract (Fig. 3h, Supplementary Fig. 10).

Function of IL-13 in vitro and in vivo. Previous work has shown that infected mice that are resistant (expel a high-dose infection) or susceptible (harbor a low-dose chronic infection) to T. muris infections make robust T. muris E/S-specific CD4+ T-helper (Th) cell recall responses and serum antibody responses ${ }^{5}$. To assess the 

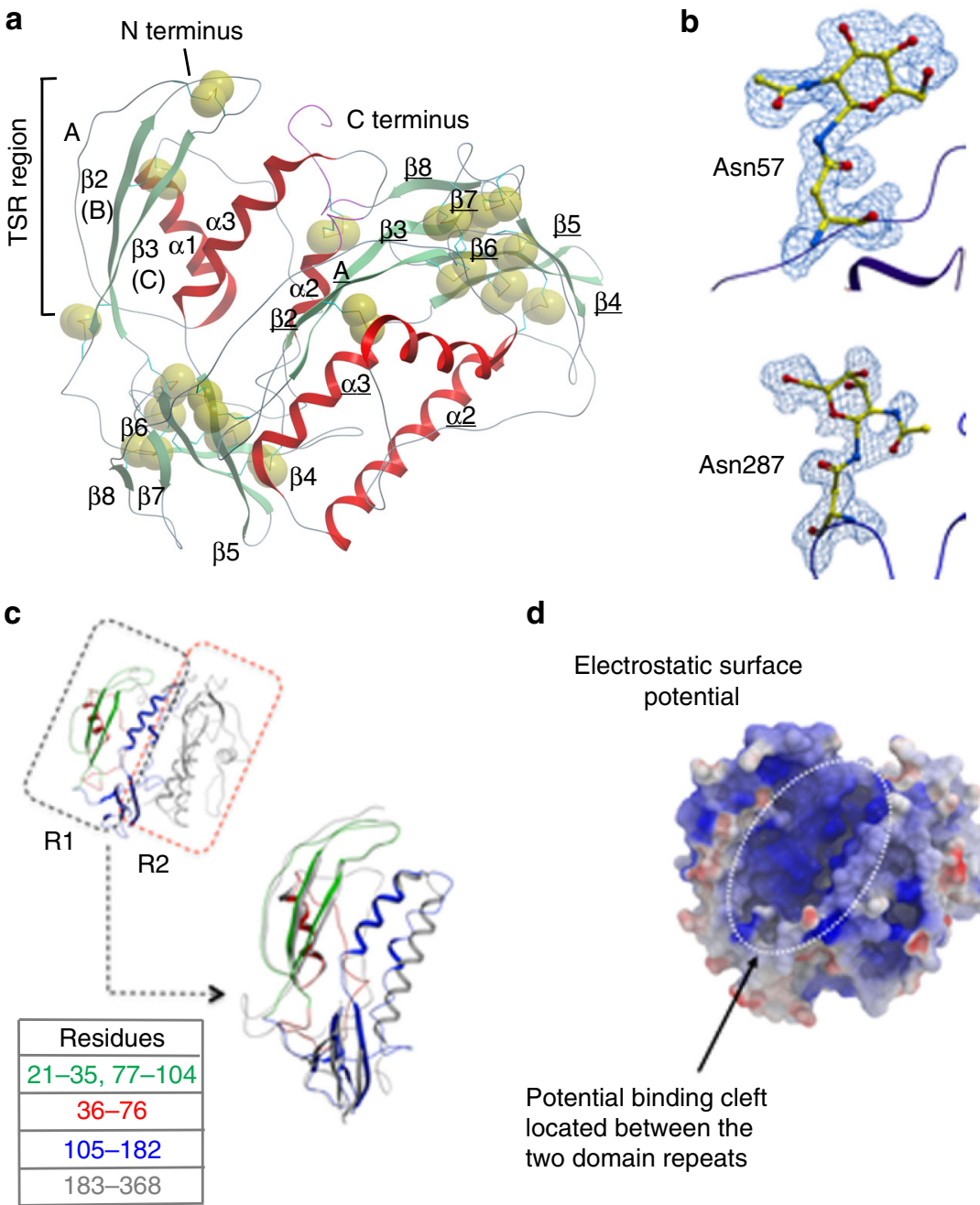

d

Electrostatic surface potential

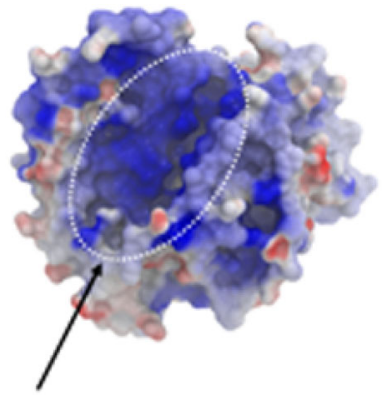

Potential binding cleft

located between the

two domain repeats

Fig. 2 Crystal structure of p43 showing glycosylation sites, thrombospondin type one domain (TSR-1), and potential binding cleft. a A ribbon representation of p43 crystal structure; helices are colored red and $\beta$-strands green. Individual helices and strands are labeled $\alpha 1, \beta 1$ for the first domain repeat and $\underline{\alpha 1}, \underline{\beta}$ for the second domain repeat. The three characteristic strands of a TSR-1 are labeled A, B, and C, respectively. The sulfur atoms are shown as Corey-Pauling-Koltun (CPK) spheres highlighting disulfide bonds. b Residues 57 and 287 are shown in an all-atom representation colored by atom type along with their associated $\mathrm{N}$-acetylglucosamine glycosylation. The electron density depicted is a feature-enhanced map (FEM) contoured at 1 sigma. Cartoon representation of the protein backbone is shown in blue. c Ribbon representation of p43 structure highlighting the domain repeat observed along with residues involved in the TSR-1 region (21-35, 77-104 in green), the $\alpha 1$ and flexible linker region (36-76 in red), and the highly disulfide linked $\beta$ sandwich region extending into $\alpha 2$ and $\alpha 3$ (105-182 in blue) forming the core of the protein. The second domain repeat is shown in ribbon representation (183-368 in gray). The two domain repeats have been superimposed based upon C- $\alpha$ positions. d Surface representation of $p 43$ colored by electrostatic surface potential calculated using the Rapid-Exact-Boundary Element (REBEL) method as implemented in ICM-PRO (blue +ve, white neutral, and red -ve). A potential binding cleft located between the two adjacent domain repeats is highlighted

contribution and importance of $\mathrm{p} 43$ to these responses, E/S in which $\mathrm{p} 43$ had been removed $\left(\mathrm{E} / \mathrm{S}^{-\mathrm{p} 43}\right)$, or purified native $\mathrm{p} 43$, were investigated by ELISA and in vitro cytokine production following acute or chronic infection. Strikingly, there was an absence of host immune response to $\mathrm{p} 43$ in comparison with both whole $\mathrm{E} / \mathrm{S}$ and $\mathrm{E} / \mathrm{S}^{-\mathrm{p} 43}$. Figure $4 \mathrm{a}, \mathrm{b}$ demonstrated that the peripheral antibody responses in mice given an acute infection, a chronic infection for 55 days, or had received repeated low-dose infections (i.e., a trickle infection), were against the minor component antigens in the E/S, E/S $-\mathrm{p}^{43}$, and not against $\mathrm{p} 43$. Similarly, in vitro recall responses of mesenteric lymph node cells (MLNCs) from T. muris-infected mice given either a high-dose (200 eggs, characterized by IL-13 production) or a low-dose infection (20 eggs, characterized by interferon- $\gamma$ (IFN- $\gamma$ ) production) showed similar cytokine profiles after re-stimulation with $\mathrm{E} / \mathrm{S}$ and $\mathrm{E} / \mathrm{S}^{-\mathrm{p} 43}$, whereas $\mathrm{p} 43$ stimulation resulted in negligible cytokine secretion, confirming lack of CD4+ T-cell priming against p43 during infection (Fig. 4c, d). To assess the capacity of $\mathrm{p} 43$ to be processed and activate antigen-presenting cells, bone marrow-derived dendritic cells (BMDDCs) were pulsed with fluorescently labeled p43, showing that p43 can localize alongside $\mathrm{H} 2-\mathrm{M}$ within the endosomal processing compartment (Supplementary Fig. 9a). Moreover, BMDDCs showed a modest dose-dependent increase in major histocompatibility complex II (MHC II) and CD86 expression following pulsing with p43, demonstrating that p43 can activate DCs (at least in vitro) similar to other archetypal helminth antigens, such as schistosomal egg antigen (SEA ${ }^{23}$; Supplementary Fig. 9b, c). However, unlike SEA, p43 does not induce downregulation of MHC II and CD86 after lipopolysaccharide stimulation 
a

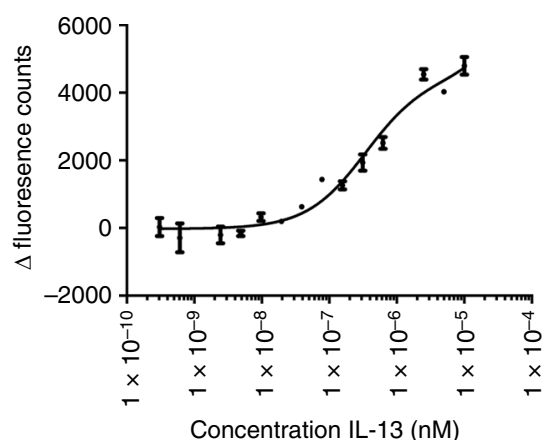

b

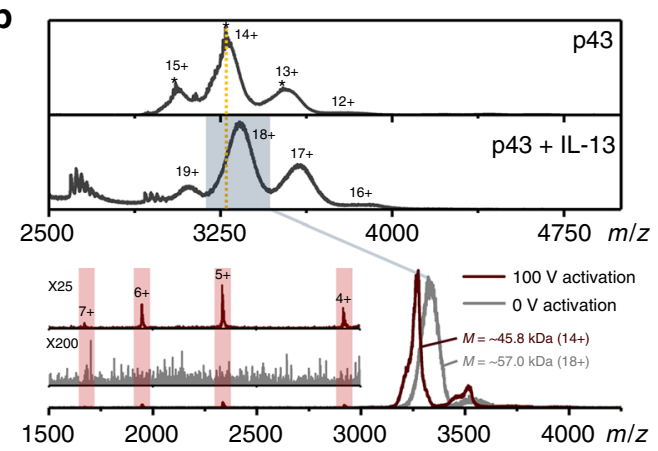

C

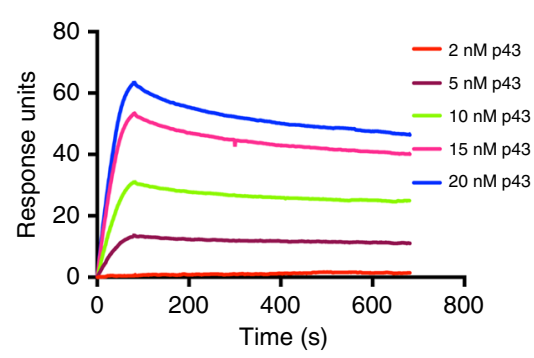

$\mathbf{f}$

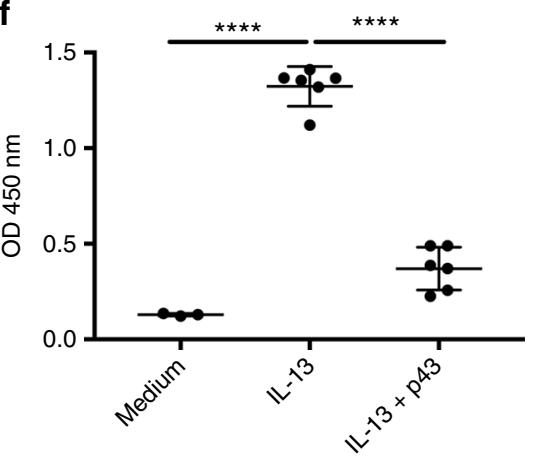

d

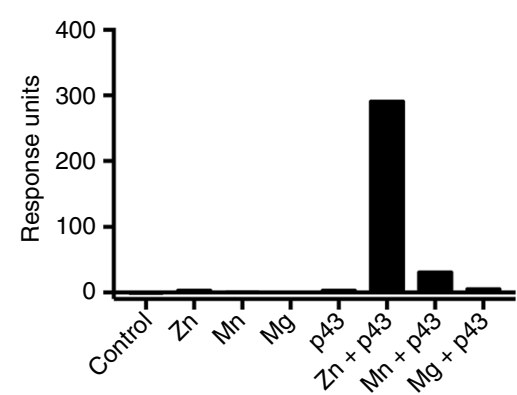

g

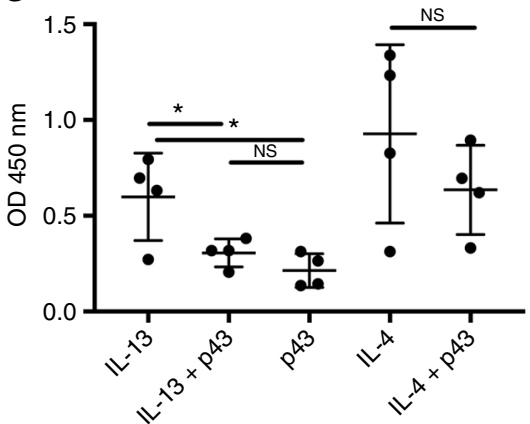

e

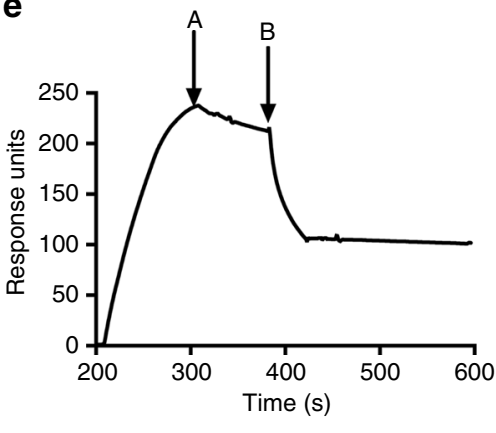

h

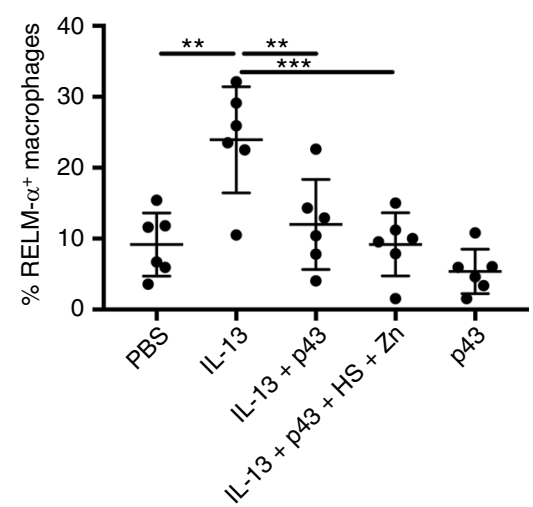

Fig. 3 p43 binds to interleukin-13 (IL-13) and the extracellular matrix in vitro. In vivo, p43 downregulates IL-13-induced inflammation. a Microscale thermophoresis (MST) of IL-13 binding to NHS-647-labeled p43. The results are the mean of three separate analyses \pm standard deviation. $\mathbf{b}$ Mass spectrum of $\mathrm{p} 43$ presenting with a narrow charge state distribution $\left(12-15^{+}\right)$of heterogenous peaks centering on the $14^{+}$charge state, upper panel. Mass spectrum of the p43:IL-13 complex is shifted to higher masses, middle panel. Collision-induced dissociation (CID) experiments were carried out on the mass-selected $18^{+}$charge state of the p43:IL-13 complex. Under "soft" tuning conditions (gray trace), the $18^{+}$charge state gave a broad peak ( $\mathrm{m} / \mathrm{z}$ of 3328 ). At a trap collision energy of $100 \mathrm{~V}$, which promotes gas-phase protein activation (red trace), the p43:IL-13 mass selected peak shifts to a lower $\mathrm{m} / z(\mathrm{~m} / z \mathrm{3260})$. The associated loss of mass of the p43:IL-13 $18^{+}$ion corresponds to the dissociation of a single IL-13 molecule (11.7 kDa). Inset peaks corresponding to the 4-7+ charge states of IL-13 at a collision energy of $100 \mathrm{~V}$, which were not present at $\mathrm{OV}$, lower panels. c Surface plasmon resonance (SPR) of biotinylated heparan sulfate (HS) and increasing amounts of p43. d SPR showing zinc-dependent binding of biotinylated HS with p43. e SPR of biotinylated HS binding to p43 with IL-13 competition ( $A$, p43 injection stops B, IL-13 injected). All in vitro experiments from $\mathbf{a}$ to $\mathbf{e}$ were repeated at least 3 times and a representative experiment has been shown. $\mathbf{f}, \mathbf{g}$ Resistin-like molecule- $\alpha$ (RELM$\alpha$ ) produced by peritoneal exudate cells (PECs) after in vitro stimulation by IL-13 \pm p43 or IL-4 \pm p43 measured by enzyme-linked immunosorbent assay (ELISA).

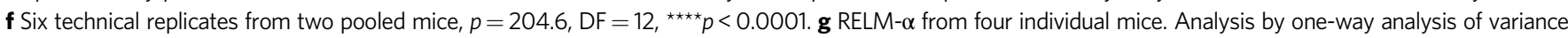
(ANOVA), $p=7.422, \mathrm{DF}=9$, IL-13 vs. IL-13 $\pm p 43,{ }^{\star} p=0.0489$. h Percentage of RELM- $\alpha$-positive interstitial lung macrophages from six individual C57BL/6 mice given administration of IL-13 $\pm \mathrm{p} 43$ to the respiratory tract. Data are from two experiments, $n=6$ individual C57BL/ 6 mice. Bars denote means $\pm \mathrm{SEM}$. Analysis by one-way ANOVA; the data passed the Shapiro-Wilk and KS normality tests, $p=10.38, \mathrm{DF}=25, \mathrm{IL}-13 \mathrm{vs}$. IL- $13 \pm \mathrm{p} 43$, ${ }^{\star \star} p=0.0063, \mathrm{IL}-13 \mathrm{vs}$. IL-13 $\pm \mathrm{p} 43+\mathrm{HS}+$ $\mathrm{Zn},{ }^{\star \star \star} \mathrm{p}=0.0007$

(Supplementary Fig. 9d, e). To test the immunogenicity of p43 in vivo, mice were immunized subcutaneously with $\mathrm{p} 43$ (together with alum) and compared to immunization with $\mathrm{E} / \mathrm{S}^{-} \mathrm{p} 43$. Vaccination with $\mathrm{p} 43$ protected mice against a challenge infection as effectively as E/S $-\mathrm{p} 43$ (Fig. 4e), indicating that $\mathrm{p} 43$ is immunogenic per se and can induce protection against infection, suggesting that immune responses targeting p43 are detrimental to parasite survival. Thus, despite a lack of immunogenicity during natural infection, p43 can function as a cryptic protective antigen. 

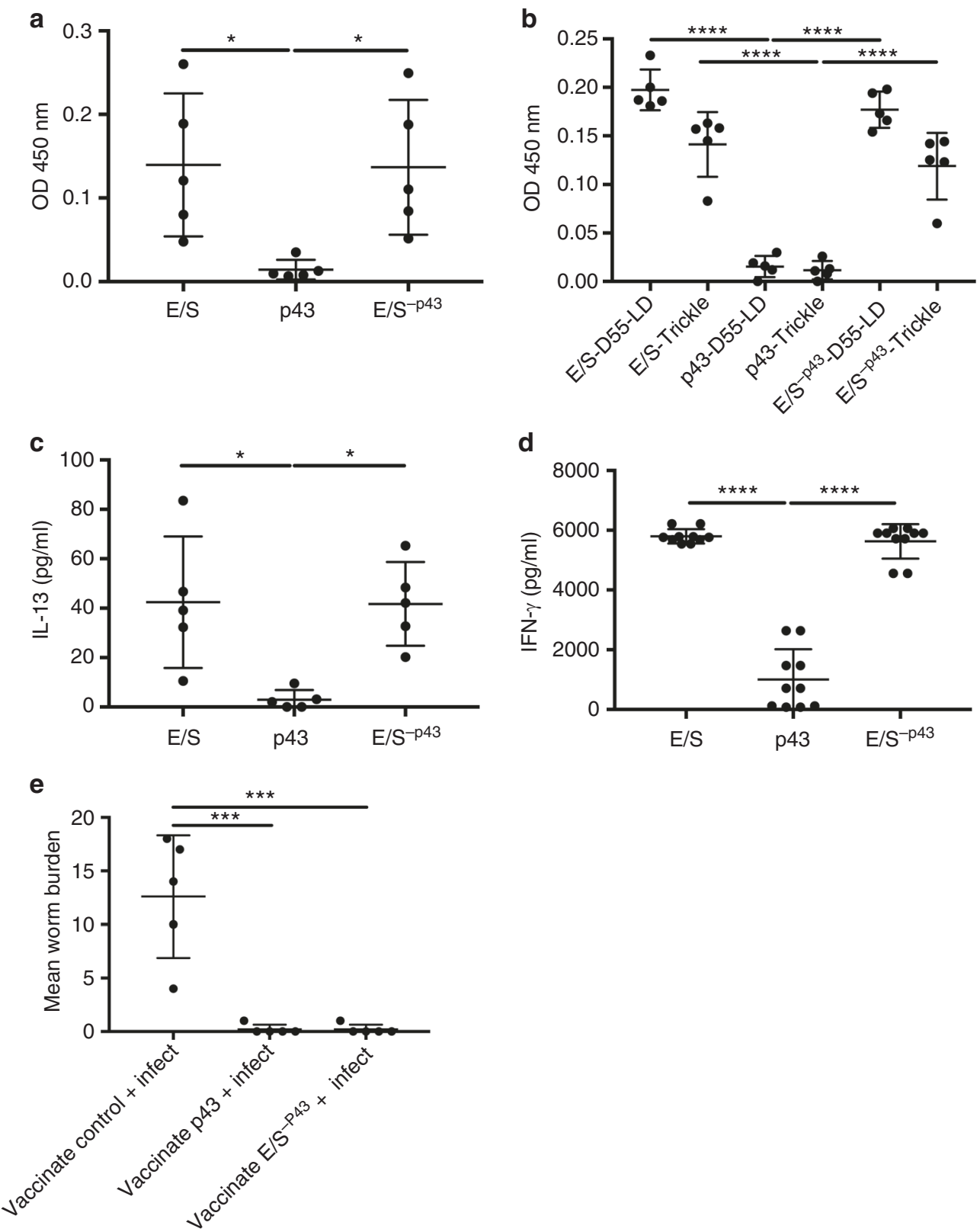

Fig. 4 There is a lack of host immune reactivity to $p 43$, although $p 43$ is successfully able to vaccinate mice against infection. a, b Anti-mouse lg (G, M, and $A$ ) enzyme-linked immunosorbent assay (ELISA) using serum from infected C57BL/6 mice. a Day 35 post infection (p.i.) serum from mice given a high-dose $T$. muris infection. b Serum from C57BL/6 mice 55 days p.i. earlier (E/S-D55-LD) or repeated low-dose (trickle) T. muris infections (day 0, 2, 4, 7, 9, and 11) at day 35 p.i. ELISA plates were coated with whole T. muris E/S, native p43, or E/S_p43, and serum was diluted at 1/80. c Interleukin-13 (IL-13) cytokine production from mesenteric lymph node cells (MLNCs) from mice infected with 200 T. muris eggs and culled at day 21 p.i. d Interferon- $\gamma$ (IFN- $\gamma$ ) production from MLNCs from mice infected with $20 \mathrm{~T}$. muris eggs and culled at day 21 p.i. In both assays, cells were restimulated with whole E/S, native p43, or ES-p43. e Worm burdens of mice at 35 days p.i. Mice were vaccinated with $50 \mu \mathrm{g}$ of $\mathrm{p} 43$, or $\mathrm{E} / \mathrm{S}^{-\mathrm{p} 43}$ subcutaneously with alum or with alum alone (vaccination control) on day -28 and day -14 p.i. and infected at day 0 with 20 T. muris eggs. Data in a-e have been repeated at least 3 times and $n=5$. Data from noninfected controls were below the detectable limits of the assay for data shown in a-d. All data are presented as mean $\pm \mathrm{SEM}$. A one-way analysis of variance (ANOVA) was used to analyze the data, a $F$ value $=5.494, \mathrm{DF}=12, \mathrm{E} / \mathrm{S}$ vs. $\mathrm{p} 43,{ }^{\star} p=0.0330, \mathrm{p} 43$ vs. E/S ${ }^{-p 43},{ }^{\star} p=0.0370 ; \mathbf{b} F=58.25, \mathrm{DF}=24$, E/S-D55-LD vs. p43-LD-D55; E/S-Trickle vs. p43-Trickle; p43-LD-D55 vs. E/S-p43-LD-D55 and p43-Trickle vs. E/S-p43-Trickle, all *** $p<0.0001 ; \mathbf{c} F=$

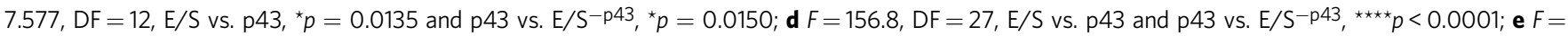
24.27, $\mathrm{DF}=12$, vaccinated control + infected vs. vaccinated $\mathrm{p} 43$ and vaccinated control + infected vs. vaccinated $\mathrm{E} / \mathrm{S}^{-\mathrm{p} 43}{ }^{\star \star \star \star} \mathrm{p}=0.0002$

\section{Discussion}

Taken together, the data suggest that the large quantities of p43 secreted by adult parasites during chronic T. muris infection may serve to interfere with the development of IL-13-dependent host protective immunity. Previous work in other helminth systems has demonstrated the potential of parasite-derived molecules in modulating immune responses either directly or indirectly primarily by influencing the initiation of immune responses or generation of regulatory cell populations ${ }^{24-26}$. In contrast, this work shows immunomodulation at the effector 
stage of the immune response, and we hypothesize that the unique structural features of $\mathrm{p} 43$ may reflect this ability, although further work is required to explore other potential cytokine ligands that may be present in the parasite niche. The composition and structure of $\mathrm{p} 43$ are consistent with a molecule that would tether to the extracellular matrix-rich environment into which it is released and be able to survive the harsh conditions that it would encounter in the microbially abundant ecosystem of the cecum and colon. Tethering to matrix molecules such as HS may also contribute to its lack of immunogenicity during infection $^{27}$. It would be interesting to further investigate the binding repertoire of $\mathrm{p} 43$ going forward. The fact that homologs of $\mathrm{p} 43$ in other trichuroid nematodes, such as the human parasite T. trichiura and T. spiralis ${ }^{28}$ are likely to be isostructural (Supplementary Fig. 4) strongly supports the hypothesis that they may play a similar role in their respective infections, particularly related to the specific intestinal epithelial niche that they all occupy. Whether p43 and "p43-like" molecules have other novel functions operating within the parasite itself or the host during infection, remains to be discovered and will require further investigation. In summary, we identify p43 as a prototype of Trichuris-derived immunomodulatory molecule with a unique structural composition that may serve as a key target for intervention in whipworm infection in man or animals by both vaccination and novel drug-based therapy. Moreover, it offers potential to inform on the development of novel cytokine inhibition strategies, with IL-13 being a critical mediator of the allergic response at mucosal surfaces.

\section{Methods}

Parasites. The Edinburgh strain of T. muris was used in all experiments originally obtained from The Wellcome Research Laboratories, London ${ }^{29}$ and is routinely passaged within our laboratory.

Animals. Male animals were used unless specifically stated at 6-8 weeks of age and were housed for 7 days prior to experimentation. C57BL/6 and BALB/c mice were purchased from Envigo (Huntingdon, UK) or Charles River (UK) and severe combined immunodeficient (SCID) mice were bred in-house at the Biological Services Facility (BSF) at the University of Manchester. Experiments were performed under the regulations of the Home Office Scientific Procedures Act (1986) and were subject to local ethical review by the University of Manchester Animal Welfare and Ethical Review Body (AWERB) and followed ARRIVE guidelines. The mice utilized in these experiments were not randomized, but cages were randomly assigned to different treatment groups for vaccination experiments.

E/S material. SCID mice were infected with 200 T. muris eggs by oral gavage. Forty two days later, mice were killed using $\mathrm{CO}_{2}$, and the cecum and proximal colon were removed. The cecum was split and washed in RPMI-1640 plus $500 \mathrm{U} /$ $\mathrm{ml}$ penicillin and $500 \mu \mathrm{g} / \mathrm{ml}$ streptomycin (all from Sigma-Aldrich, UK). Worms were removed using fine forceps and cultured for $4 \mathrm{~h}$ in RPMI-1640 plus penicillin/ streptomycin as above at $37^{\circ} \mathrm{C}$. The E/S from worm culture was centrifuged to pellet the eggs and filtered through a syringe filter of $0.22 \mu \mathrm{m}$ (Sartorius, Gottingen, Germany). After concentration using centrifugal filter units (Merck ${ }^{\mathrm{m}}$ Amicon, Fisher Scientific, UK) and dialysis against phosphate-buffered saline (PBS), the concentration of the E/S was determined using a Nanodrop (Labtech International, Heathfield, UK). It was aliquoted and stored at $-20^{\circ} \mathrm{C}$ until use.

Western blot. Mucus samples extracted from T. muris infected or naive animals were analyzed on $4-12 \%(w / v)$ RunBlue ${ }^{\text {Th }}$ SDS precise gels (Expedeon Ltd, Cambridgeshire, UK). Samples were prepared using RunBlue rapid SDS running buffer (Expedeon Ltd, Cambridgeshire, UK) and reduced in $50 \mathrm{mM}$ dithiothreitol (SigmaAldrich, UK) for $10 \mathrm{~min}$ at $95^{\circ} \mathrm{C}$. Precision Plus Protein All Blue Standards (BioRad Laboratories, Hertfordshire, UK) were used as molecular weight markers. Gels were run in XCell II Mini-cell electrophoresis tanks (Novex, San Diego, CA, USA) at $200 \mathrm{~V}$ for $60 \mathrm{~min}$. Following electrophoretic separation, gels were analyzed for the presence of T. muris $\mathrm{p} 43$ in the mucus extract. The proteins were transferred onto a nitrocellulose membrane using an XCell IITM semi-wet Blot Module (Invitrogen, Thermo Fisher Scientific, UK) and run at $60 \mathrm{~V}$ for $90 \mathrm{~min}$ in $20 \%$ methanol in NuPAGE transfer buffer (Novex, San Diego, CA, USA). The membrane was briefly washed in Tris (hydroxymethyl amino methane)-buffered saline (TBS), polyoxyethylene sorbitan monolaurate (Tween-20) (Sigma-Aldrich, UK),
$0.05 \%$ TBS Tween-20, and blocked in 5\% nonfat milk (Marvel, UK) overnight at $4^{\circ}$ C. It was probed with polyclonal rabbit anti-p43 (raised against the native peptide sequence, Cambridge Research Biochemicals, Billingham, UK) and diluted 1/1000 in $5 \%$ nonfat milk for $90 \mathrm{~min}$ at room temperature. The membrane was washed in TBS Tween-20 5 times for $5 \mathrm{~min}$, and then incubated for an hour with 800-nm goat anti-rabbit (926-32211, LI-COR, NE, USA) diluted $1 / 25,000$ in 1\% TBS Tween-20, and subsequently washed in 1\% TBS Tween-20 4 times for 5 min with a final wash step in PBS. Blots were scanned on the LI-COR Odyssey CLx Infrared Imaging System (Li-COR Biotechnology-UK Ltd, Cambridge, UK).

Secreted mucus extraction. Mouse intestines were removed and placed in a 12 well plate (Corning, NY, USA) on ice. The cecum and colon were separated and the fecal matter gently removed. The colon and cecum were cleaned by flushing the lumen with $2 \mathrm{ml}$ of PBS using a blunt needle tip and a $2.5-\mathrm{ml}$ syringe. The flowthrough was collected and passed through the tissue again and retained in a $14-\mathrm{ml}$ Falcon tube (Corning, NY, USA). Following PBS washes, the colons were flushed 5 times with $2 \mathrm{ml}$ of $2 \mathrm{M}$ urea (Melford, Ipswich, UK), and the flow-through was kept in a fresh clean tube. The cecal tissues were opened longitudinally and placed in 2 $\mathrm{ml}$ of $2 \mathrm{M}$ urea and gently rotated for $1 \mathrm{~min}$. Before and after mucus extraction, gut tissue snips were taken for histological analysis to ascertain whether any damage had occurred to the epithelium and if crypts were intact. The flow-through of PBS and $2 \mathrm{M}$ urea flushes of each mouse were kept at $4{ }^{\circ} \mathrm{C}$ overnight and then concentrated using Sartorius Vivaspin 3-kDa molecular weight cutoff (MWCO) columns (Gottingen, Germany) spinning for $10 \mathrm{~min}$ at $19,000 \times g$. The solvent was exchanged to $6 \mathrm{M}$ urea and all samples were at a volume of $200 \mu \mathrm{l}$. The mucus extracts were subjected to tandem mass spectrometry and SDS-PAGE analysis.

Immunostaining. Five-micrometer sections were cut from the cecum of mice infected with 200 eggs of T. muris. After overnight drying at $42{ }^{\circ} \mathrm{C}$, the sections were incubated in citroclear (TCS Biosciences, Buckingham, UK) for 5 min and then incubated in $100 \%$ ethanol and a gradient of $90 \%, 70 \%$, and $50 \%$ ethanol for 2 min, followed by distilled $\mathrm{H}_{2} \mathrm{O}$ for $2 \mathrm{~min}$. Sections were incubated in PBS for $5 \mathrm{~min}$. The sections were blocked with $10 \%$ goat serum (Sigma-Aldrich, UK) for $30 \mathrm{~min}$ The anti-p43-kDa antibody (Cambridge Research Biochemicals, Billingham, UK) was used at $1 / 400$ in $1 / 10$ blocking buffer overnight at $4{ }^{\circ} \mathrm{C}$. The next day after washing in PBS, sections were incubated in goat anti-rabbit Alexa Fluor 488 (A11034, Invitrogen, Thermo Fisher Scientific, UK) 1/800 in PBS for $1 \mathrm{~h}$. Further washing in PBS was followed by incubation in $0.1 \%$ Sudan Black (Sigma-Aldrich, UK) in $70 \%$ ethanol in the dark. After a final wash in PBS, slides were allowed to air-dry and mounted in Mowiol ${ }^{\oplus}$ 4-88 (Sigma-Aldrich, UK) mounting medium plus or minus 4',6-diamidino-2-phenylindole, dihydrochloride (DAPI) (Sigma-Aldrich UK). Images were collected on a Leica TCS SP5 AOBS inverted confocal microscope (Leica Microsystems, Milton Keynes, UK) using a $\times 20 / 0.50$ Plan Fluotar objective and $\times 3$ confocal zoom. The confocal settings were as follows: pinhole (1 airy unit), scan speed $(1000 \mathrm{~Hz}$ unidirectional), and format $(1024 \times 1024)$. Images were collected using (hybrid) detectors with the following detection mirror settings: fluorescein isothiocyanate (FITC) $494-530 \mathrm{~nm}$, using the white light laser with 488 $\mathrm{nm}(20 \%)$. When acquiring 3D optical stacks, the confocal software was used to determine the optimal number of $\mathrm{Z}$ sections. Only the maximum intensity projections of these $3 \mathrm{D}$ stacks are shown in the results. A Coolsnap ES2 camera (Photometrics, AZ, USA) was used to capture the images using Metavue $\mathrm{v}$ 7.8.4.0 software (Molecular Devices, CA, USA). Images were then processed and analyzed using Fiji software. FISH-infected mice were killed and their ceca removed. They were cut longitudinally and cecal contents removed in PBS. The cecum and proximal colon were cut into small sections and incubated in $4 \%$ paraformaldehyde for $60 \mathrm{~min}$ at room temperature. The sections were then washed in PBS and transferred to $70 \%$ ethanol and stored at $-80^{\circ} \mathrm{C}$ until use. Tissue processing was carried out using an automated tissue processor, Shandon Citadel 2000 (Thermo Scientific, UK), and the sections were embedded in paraffin wax. Five-micrometer sections were cut using a Leica RM 2235 microtome (Leica Biosystems, Milton Keynes, UK).

Fluorescent in situ hybridization. For generation of the RNA probes, messenger RNA (mRNA) was extracted from adult worms by maceration in Trizol (Life Technologies, Thermo Fisher Scientific, UK) with a FastPrep and lysing matrix D (MP Biomedical, Fisher Scientific, UK). The p43 cDNA template to generate RNA probes was obtained by reverse transcriptase PCR from extracted mRNA using Superscript III (Invitrogen, Thermo Fisher Scientific, UK), followed by PCR amplification of $\mathrm{p} 43$ using specifically designed primers and Phusion DNA polymerase (NEB, UK). The following primers were used for $\mathrm{p} 43$ : forward, 5'-GCAA TGCTTCACTCGACCCG-3' and reverse, 5' $^{\prime}$-TTGTGGTGCTCCTCTCCGTG-3'. For myosin, the following primers were designed from WormBase ParaSite ${ }^{30}$ using the T. muris genome and a paralog sequence of myosin 3 from Caenorhabditis elegans. The primer sequences used were as follows: forward, $5^{\prime}$-GCAGATCGTCATGACCAACC-3' and reverse, 5'-GTCATGTCGCTTGCCTTAGG$3^{\prime}$. PCR products were TA cloned into PCR2.1 TOPO vector and sequenced to confirm. For the antisense RNA probe, pCR2.1-p43 was linearized with BamHI (NEB) and transcribed with T7 RNA polymerase (Promega, WI, USA). For the 
sense RNA probe, pCR2.1-p43 was linearized with NotI (NEB, MA, USA) and transcribed with SP6 RNA polymerase (Promega, WI, USA). In both cases, digoxigenin (Dig) RNA labeling mix (Sigma-Aldrich, UK) was used to label each probe with a Dig epitope.

Paraffin sections were dewaxed twice for $10 \mathrm{~min}$ in fresh xylene and then slowly rehydrated by consecutive washes for $5 \mathrm{~min}$ in $100 \%, 90 \%$, and $70 \%$ ethanol. Sections were then washed twice for $5 \mathrm{~min}$ in diethyl pyrocarbonate-treated water. FISH on the rehydrated sections was carried out as described ${ }^{31}$. Dig epitopes were detected by tyramide amplification using TSA Plus Cyanine 3 kit (Perkin-Elmer, MA, USA). The slides were visualized using an inverted confocal microscope, Olympus Fluoview FV-100.

Electron microscopy. The samples were fixed with $4 \%$ formaldehyde and $2.5 \%$ glutaraldehyde in 0.1 M 4-(2-hydroxyethyl)-1-piperazineethanesulfonic acid (HEPES) buffer ( $\mathrm{pH} 7.2$ ). They were then post fixed with $1 \%$ osmium tetroxide, $1.5 \%$ potassium ferrocyanide in $0.1 \mathrm{M}$ cacodylate buffer $(\mathrm{pH} 7.2)$ for $1 \mathrm{~h}$, and then overnight in $1 \%$ uranyl acetate in water. The samples were dehydrated in an ethanol series infiltrated with TAAB 812 resin (TAAB, Berks, UK) and polymerized for $24 \mathrm{~h}$ at $60^{\circ} \mathrm{C}$. Sections were cut with Reichert Ultracut ultramicrotome and observed with FEI Tecnai 12 Biotwin microscope (OR, USA) at 100-kV accelerating voltage. Images were taken with Gatan Orius SC1000 CCD camera.

For immunoelectron microscopy, the samples were fixed with $4 \%$ formaldehyde and $0.1 \%$ glutaraldehyde in $0.1 \mathrm{M}$ HEPES buffer $(\mathrm{pH} 7.2)$. After dehydration in an ascending gradient of ethanols, specimens were infiltrated with LR White (London Resin Company, Reading, UK) and polymerized at $40^{\circ} \mathrm{C}$ for $48 \mathrm{~h}$. Ultrathin sections were cut with Reichert Ultracut ultramicrotome. For immunolabeling, sections were washed with $0.1 \mathrm{M}$ phosphate buffer, blocked with $1 \%$ bovine serum albumin (BSA) in 0.1 M PBS, and incubated with rabbit anti-p43 (Cambridge Research Biochemicals, Billingham, UK) for $1 \mathrm{~h}$. Then, sections were washed with $0.1 \mathrm{M}$ PBS and incubated with anti-rabbit conjugated with colloidal gold particles (SKU\# EM:PAG15, BBI Solutions, Tebu-bio, Cambs, UK). They were fixed with 1\% glutaraldehyde and after washing with distilled water were stained with $1 \%$ uranyl acetate. Samples were observed with FEI Tecnai 12 Biotwin microscope at $100-\mathrm{kV}$ accelerating voltage. Images were taken with Gatan Orius SC1000 CCD camera.

p43-Native p43 isolation. Trichuris muris adult worms were collected from the cecum of mice on day 42 post infection. They were cultured for up to $24 \mathrm{~h}$ in RPMI- 1640 plus 500 international units $/ \mathrm{ml}$ (IU) penicillin and $500 \mu \mathrm{g} / \mathrm{ml}$ streptomycin (Invitrogen, Thermo Fisher Scientific, UK). The culture medium containing E/S proteins was pelleted at $720 \times g$ for $15 \mathrm{~min}$ to remove eggs. E/S in $50-\mathrm{ml}$ Falcon tubes (Corning) was filtered through a $0.22-\mu \mathrm{m}$ syringe filter (Sartorius) and incubated overnight with end-over-end mixing at $4{ }^{\circ} \mathrm{C}$ with $5 \mathrm{mM}$ imidazole and 2 $\mathrm{ml}$ of Ni NTA agarose (Qiagen, Manchester, UK). The next day, two washes were performed using $25 \mathrm{mM}$ Tris, $150 \mathrm{mM}$ sodium chloride, $\mathrm{pH} 7.9$, and 20 and $40 \mathrm{mM}$ imidazole. p43 was eluted from the beads in $250 \mathrm{mM}$ imidazole as $10 \times 1-\mathrm{ml}$ fractions. The eluate was run on a gel to check for $\mathrm{p} 43$ in the fractions. It was then further purified on a size-exclusion column Superdex 75 (GE Healthcare) in 20 $\mathrm{mM}$ Tris and $50 \mathrm{mM} \mathrm{NaCl}, \mathrm{pH}$ 7.9. Zero point five milliliter fractions were eluted and run on $4-12 \%$ Bis-Tris gel to confirm the p43-containing fractions. p43 was concentrated using a centrifugal filter unit, 10-kDa MWCO (Millipore), and sterilized using a syringe filter with a $0.22-\mu \mathrm{m}$ pore size. $\mathrm{p} 43$ concentration was determined using a Nanodrop (Labtech International, UK), and protein was aliquoted and stored at $-80^{\circ} \mathrm{C}$, until required for experimental use.

Excretory/secretory products without $\mathbf{p 4 3}$. E/S products that did not bind to nickel beads in the overnight incubation, was termed $\mathrm{E} / \mathrm{S}^{-\mathrm{p} 43}$. This was concentrated using a centrifugal filter unit, $10-\mathrm{kDa}$ MWCO (Millipore), and then buffer exchanged into PBS, pH 7.4. Later, it was filter sterilized using a syringe filter with a $0.22-\mu \mathrm{m}$ pore size, aliquoted, and then stored at $-80^{\circ} \mathrm{C}$ until use. Removal of $\mathrm{p} 43$ was confirmed using SDS-PAGE.

r43-Recombinant, baculovirus-derived $\mathrm{p} 43$ production. The $\mathrm{p} 43$ gene minus signal peptide (aa 18-394) was amplified using a DNA template originally from a T. muris cDNA library using the following PCR primers: forward, $5^{\prime}$-CTCGTCG GATCCCGGTCACGTAAAATGTCCGGAC- $3^{\prime}$ and reverse primer, 5'-CTCGTC GAATTCTCAGTGGTGGTGGTGCTCCTTG- $3^{\prime}$. The PCR was carried out using $P f u$ (Strategene, CA, USA) with the following conditions: $94^{\circ} \mathrm{C}$ for $1 \mathrm{~min}$, followed by 30 cycles of $94^{\circ} \mathrm{C}$ for $15 \mathrm{~s}, 55^{\circ} \mathrm{C}$ for $30 \mathrm{~s}$, and $72^{\circ} \mathrm{C}$ for $1.5 \mathrm{~min}$, and then $72^{\circ} \mathrm{C}$ for $10 \mathrm{~min}$ and $4{ }^{\circ} \mathrm{C}$ hold. The PCR was resolved on a $1 \%$ agarose gel and excised (Qiagen Gel Extraction Kit), and then digested with BamHI and EcoRI enzymes (Fermentas, Thermo Fisher Scientific) and purified using a PCR cleanup column (Qiagen, Manchester, UK). Baculovirus transfer plasmid pAcGP67 (Pharmingen) was also digested with both enzymes and the linearized vector gel purified (Qiagen, Manchester, UK). Ligation was performed using T4 DNA ligase (NEB) and ligation reactions transformed into competent JM109 cells. Sequence confirmation of the construct was carried out using both forward- and reverse-specific vector primers (GATC).

For insect cell protein expression and purification, pAcGP67:T. muris $\mathrm{p} 43$ (18-394) construct was co-transfected into Sf9 cells with flashBAC ultra DNA
(Oxford Expression Technologies). Secreted virus was removed after 4 days and used to amplify $50 \mathrm{ml}$ of Sf9 cells $\left(2 \times 10^{6}\right.$ cells $\left./ \mathrm{ml}\right)$ in a $250-\mathrm{ml}$ sterile Erlenmeyer flask for a further 5 days $\left(120\right.$ r.p.m. at $\left.28^{\circ} \mathrm{C}\right)$. Virus was titrated using a conventional plaque assay. Hi5 cells were infected with recombinant T. muris $\mathrm{p} 43$ virus at a multiplicity of infection (MOI) of 5 and left for $72 \mathrm{~h}$ to secrete. Media were collected and cells were removed by centrifugation $(720 \times g$ for $5 \mathrm{~min})$. Secreted protein was purified from the media as for $\mathrm{p} 43$, although no size-exclusion purification step was necessary. Prior to crystallogenesis, selenomethionine (SeMet) labeling of p43 was undertaken. Hi5 cells (Invitrogen) were first adapted to growth in ESF921 media lacking methionine (Expression Systems) by growing for at least six passages: Cells were grown to a density of $2 \times 10^{6} / \mathrm{ml}$ and infected with recombinant $\mathrm{p} 43$ baculovirus. After $16 \mathrm{~h}$, DL-selenomethionine (Generon) at $50 \mathrm{mg} / \mathrm{l}$ was added and the culture was left for a further $48 \mathrm{~h}$.

Crystallogenesis. Recombinant SeMet-derivatized p43 was crystallized by sittingdrop vapor diffusion. The purified protein was concentrated to a final concentration of $8 \mathrm{mg} / \mathrm{ml}$ in $20 \mathrm{mM}$ Tris/ $\mathrm{HCl}$ at $\mathrm{pH} 7.9$. Two-hundred nanoliters of protein was mixed with an equal volume of reservoir solution from five commercially available crystallization screens (JCSG-plus, PACT Premier, Clear Strategy I + II and Morpheus) using a Mosquito (TTP) nanoliter pipetting robot and incubated at $4{ }^{\circ} \mathrm{C}$ for $16 \mathrm{~h}$.

Following primary crystallogenesis, Matrix seeding ${ }^{32}$ was used to rapidly optimize the available crystals. Initial crystal hits were aspirated along with $50 \mu \mathrm{l}$ of reservoir solution and added to a Seed Bead apparatus. The seed stock was then generated by vortexing for $90 \mathrm{~s}$ before being placed on ice and used immediately without any further dilution. The matrix-seeded sitting drops were set with $180 \mathrm{nl}$ of protein, $20 \mathrm{nl}$ of seed stock, and $200 \mathrm{nl}$ of reservoir solution. These drops were then incubated at $4{ }^{\circ} \mathrm{C}$ for a further $16 \mathrm{~h}$. Following incubation, single crystals suitable for X-ray analysis were harvested from ( $0.2 \mathrm{M}$ lithium sulfate, $0.1 \mathrm{M}$ Tris, $\mathrm{pH} 8.5$, and $40 \%$ Peg 400 [JCSG D7]) and flash frozen by plunge freezing in liquid nitrogen. Native p 43 was also crystallized and optimized in a similar manner to that described above. Single crystals suitable for X-ray analysis were harvested from Morpheus G9 and flash frozen by plunge freezing in liquid nitrogen.

Data collection and structure determination. Data were collected from single cryo-frozen crystals of SeMet p43 at Diamond Light Source Beamline (i03). A complete dataset was collected at a wavelength of $(0.9795 \AA)$ and subsequently scaled and merged using $\mathrm{Xia}_{2}{ }^{33}$. The structure was determined using singlewavelength anomalous dispersion in SHELX. An initial model was autobuilt, which clearly described the main secondary structural elements of $\mathrm{p} 43$. Data were also collected from a single cryo-frozen crystal of natively expressed p43 at Diamond, Beamline (i03). A complete dataset was collected and subsequently scaled and merged using Xia2. Following initial phasing, the partial autobuilt structure was used as the basis for molecular replacement against the native data. A model of the native p 43 structure was subsequently completed and refined using iterative cycles of rebuilding and refinement in COOT $^{34}$ and Phenix.refine ${ }^{35}$. Validation with Molprobity and PDB-REDO was integrated into the iterative rebuilding and refinement process ${ }^{36}$. Complete data collection and refinement statistics are presented in Supplementary Table 2. The crystal structure of p 43 contains two monomers in the asymmetric unit; analysis with both size-exclusion chromatography and PISA (http://www.ebi.ac.uk/pdbe/prot_int/pistart.html) indicates that p43 is unlikely to form higher-order assemblies in solution ${ }^{37}$.

Microscale thermophoresis. p43 $(20 \mu \mathrm{M})$ was labeled with NHS-647 red dye (NanoTemper, Cambridge), using a 3:1 ratio of dye to protein, and the reaction was left for $30 \mathrm{~min}$ at room temperature. Unbound NHS-647 was removed from that bound to p43 using a 5-ml desalting column pre-equilibrated in sample buffer (20 $\mathrm{mM}$ HEPES, $150 \mathrm{mM} \mathrm{NaCl}$, and $0.005 \%$ Tween-20, $\mathrm{pH}$ 7.4). The final concentration of labeled p43 was $\sim 5 \mu \mathrm{M}$ and this was used as the stock solution for binding experiments. IL-13 (recombinant murine IL-13, PMC0135, Thermo Fisher USA) was resuspended to a concentration of $40 \mu \mathrm{M}$ in sample buffer, and a serial dilution from $2500 \mathrm{nM}$ to $40 \mathrm{pM}$ was incubated with $5 \mathrm{nM} \mathrm{p} 43$, as per the instructions on the instrument software. Samples were loaded into premium coated capillaries and analyzed with an LED power (which regulates the level of fluorescence) of 5\% and an MST power (which creates the temperature gradient for MST to occur) of $40 \%$ on a Monolith Pico instrument (NanoTemper). The response amplitude of MST change was $\sim 9.5$, and the signal-to-noise ratio was $\sim 19$. The sample was run with three different reactions and the results fitted with a $K_{D}$ model (1:1 stoichiometry) within the MO-Analysis software (NanoTemper, Germany).

Native mass spectrometry. Twenty micromoles p 43 in PBS was buffer exchanged 4 times into $250 \mathrm{mM}$ ammonium acetate, $\mathrm{pH}$ 7, using Biospin- 6 columns (Bio-Rad, USA). Lyophilized recombinant mouse IL-13 was dissolved in $250 \mathrm{mM}$ ammonium acetate, $\mathrm{pH} \mathrm{7}$, and buffer exchanged once in order to remove non-volatile salt adducts. For the binding experiments, $\mathrm{p} 43$ and IL-13 were mixed at a ratio of 1.5:1 respectively, and left to incubate at room temperature for $2 \mathrm{~h}$ prior to analysis.

All experiments were performed using nano-electrospray ionization in positive ionization mode. Mass spectra and arrival time distribution profiles were recorded 
on a Synapt G2-Si traveling-wave ion-mobility mass spectrometer (Waters, Manchester, UK). Typical source parameters utilized were as follows: capillary voltage, $\sim 0.9-1.2 \mathrm{kV}$; sample cone, $\sim 20 \mathrm{~V}$; source temp, $60^{\circ} \mathrm{C}$; Trap gas, $4 \mathrm{ml} / \mathrm{min}$. Stepwave voltages were also optimized so as to promote ion transmission and sample cleanup while minimizing structural perturbations. Ion charge states corresponding to specific $\mathrm{m} / \mathrm{z}$ values were mass selected within the quadrupole prior to CID experiments. CID was carried out with argon as the collision gas within the trap cell region. Data were acquired and processed with MassLynx V4.1 software (Waters, Manchester, UK). Mass spectra were deconvoluted using the UniDec software ${ }^{38}$. Error in the calculated experimental masses of $\mathrm{p} 43$ and the p43-IL-13 complex were obtained from the full-width half-maxima for the center of mass of both species.

Surface plasmon resonance. SPR was used to investigate the binding of p43 to HS. HS was biotinylated at the reducing end by reductive amination ${ }^{39}$. Briefly, HS (low molecular weight fraction-1 from porcine mucosa, Iduron, UK) was dissolved in $2 \mathrm{M}$ ammonium chloride $\left(\mathrm{NH}_{4} \mathrm{Cl}\right)$, in a volume of $100 \mu$. Two milligrams of sodium borocyanohydride $\left(\mathrm{NaCNBH}_{3}\right)$ was added, and the mixture was heated at $70{ }^{\circ} \mathrm{C}$ for 2 days. Following dialysis into PBS, $10 \mu \mathrm{l}$ of $3 \mathrm{mg} / \mathrm{ml}$ sulfosuccinimidyl-6(biotinamido) hexanoate (Sulfo-NHS-LC-Biotin, Thermo) was added and incubated overnight at $4^{\circ} \mathrm{C}$. Non-reacted biotin was then removed by further dialysis into $0.1 \mathrm{M}$ sodium acetate, $\mathrm{pH} 5.5$.

Streptavidin sensors (SA-chips) were used in a Biacore T200 instrument (GE Healthcare) with a running buffer of $10 \mathrm{mM}$ HEPES, $150 \mathrm{mM} \mathrm{NaCl}$, and $0.005 \%$ Tween-20 both with and without zinc. For kinetic analysis, the surface was loaded with $\sim 50 \mathrm{U}$ of Biotin-HS in running buffer with $50 \mu \mathrm{M}$ zinc chloride. p43 was injected at concentrations of $0,2,5,10,15,20$, and $25 \mathrm{nM}$ with an 80-s injection and a 600-s dissociation before regeneration with $10 \mathrm{mM}$ ethylenediaminetetraacetic acid (EDTA). Analyte sensograms were analyzed in BIAevaluation version 3.1 with a 1:1 Langmuir model fitted with a global R-Max.

Investigation into the dependence of ions on 443 binding to HS was conducted on a Biotin-HS surface of $\sim 100 \mathrm{U}$ of HS. In these experiments, the running buffer did not contain zinc. p43 was injected at a concentration of $100 \mathrm{nM}$ in solutions containing running buffer plus $20 \mu \mathrm{M}$ of cobalt, copper, iron, nickel, zinc, calcium magnesium, and manganese. In each case, the sample was injected for $60 \mathrm{~s}$, and immediately the HS surface was washed with $10 \mathrm{mM}$ EDTA prior to injection of the next sample. Total binding was selected as the response level at $60 \mathrm{~s}$ following injection.

IL-13 competition was performed using a surface coverage of $\sim 200 \mathrm{U}$ of biotinylated $\mathrm{HS}$ in running buffer with $50 \mu \mathrm{M}$ zinc chloride, $\mathrm{ZnCl}_{2} \mathrm{p} 43$ was injected at a concentration of $100 \mathrm{nM}$ for $60 \mathrm{~s}$ before injection of IL-13 at a concentration of $1 \mu \mathrm{M}$ diluted in running buffer plus $50 \mu \mathrm{M} \mathrm{ZnCl}_{2}$. Inhibition of $\mathrm{p} 43$ binding to HS was performed on the same HS surface by injection of $\mathrm{p} 43$ as the analyte with the addition of increasing concentrations of IL-13 to p43 prior to injection. Samples were incubated for $10 \mathrm{~min}$ prior to injection.

Peritoneal cell isolation. Female, C57BL/6 mice were injected intraperitoneally (i. p.) with $4 \%$ thioglycolate (Becton Dickinson). Three days later, mice were killed under $\mathrm{CO}_{2}$ and 5-7 ml of ice-cold RPMI-1640,5\% fetal calf serum (FCS), was injected i.p. After massaging, the injected medium was withdrawn and the cells were collected in a 15-ml tube (Corning). The cells were pelleted and washed once with the medium before counting using a CASY automated cell counter. A total of $1 \times 10^{6}$ cells $/ \mathrm{ml}$ were plated in a 24 sterile tissue culture plate. After $3 \mathrm{~h}$, the medium was replaced by either fresh medium, medium containing $20 \mathrm{ng} / \mathrm{ml}$ of recombinant mouse (rm)IL-13, $20 \mathrm{ng} / \mathrm{ml} \mathrm{rmIL-13,} \mathrm{and} 20 \mu \mathrm{g} / \mathrm{ml}$ of p 43 or $20 \mu \mathrm{g} / \mathrm{ml}$ p43 alone. In a repeat experiment, $20 \mathrm{ng} / \mathrm{ml} \mathrm{rmIL}-4$ and IL-4 plus p43 were used. All conditions contained $100 \mu \mathrm{g} / \mathrm{ml} \mathrm{HS}$ and $100 \mathrm{mM}$ zinc $\left(\mathrm{ZnCl}_{2}\right)$. The plates were left at $37^{\circ} \mathrm{C}$ in $5 \% \mathrm{CO}_{2}$. Forty-eight hours later, the cells and medium were taken, centrifuged to pellet the cells, and the supernatant was assayed for RELM- $\alpha$ by ELISA.

RELM- $\boldsymbol{\alpha}$ ELISA. ELISA plates (Greiner, GmbH, Austria) were coated at $1 \mu \mathrm{g} / \mathrm{ml}$ with rabbit anti-mouse RELM- $\alpha$ (Peprotech, UK) and incubated overnight at $4{ }^{\circ} \mathrm{C}$. The next day, the plates were washed $5 \times$ with PBS $+0.05 \%$ Tween- 20 , and a blocking step was carried out using PBS $+10 \%$ FCS for $1 \mathrm{~h}$ at room temperature. Supernatants from peritoneal macrophages were diluted and added to the plates for $1 \mathrm{~h}$. After washing again, the plates were incubated with $1 / 200$ biotinylated rabbit anti-mouse RELM- $\alpha$ (Peprotech, UK) for $1 \mathrm{~h}$ at room temperature. The plates were subsequently washed and developed with 3,3',5',5-tetramethylbenzidine. The reaction was stopped with $0.18 \mathrm{M} \mathrm{H}_{2} \mathrm{SO}_{4}$, and the plates were read on a VersaMax ELISA reader (Molecular Devices, CA, USA), and the data were analyzed using the SoftMax Pro 6.4.2 software.

Intranasal administration of IL-13 $\pm \mathbf{p 4 3}$, zinc, and HS. PBS, $5 \mathrm{ng}$ of recombinant murine IL-13, and $45 \mu \mathrm{g}$ of r 43 were given intranasally (i.n.), singly, or in combination together with or without $\mathrm{Zn}$ and HS. All preparations were made up and stored at $4{ }^{\circ} \mathrm{C}$ overnight before administration. Fifty microliters were administered to each mouse under anesthesia $24 \mathrm{~h}$ prior to killing.
Isolation of immune cells from the lung. Following killing, bronchoalveolar cells were obtained by washing of the cavity or lungs with PBS containing $2 \%$ FCS (Sigma) and $2 \mathrm{mM}$ EDTA (Thermo Fisher). Lungs were processed as previously described $^{20}$, and incubated at $37^{\circ} \mathrm{C}$ for $40 \mathrm{~min}$ with $0.8 \mathrm{U} / \mathrm{ml}$ Liberase TL (Roche Diagnostics) and $80 \mathrm{U} / \mathrm{ml}$ DNase I type VI in HBSS (both Sigma). The digestion was stopped with PBS containing 2\% FCS (Sigma) and $2 \mathrm{mM}$ EDTA (Thermo Fisher), and the resulting suspension was then passed through a $70-\mu \mathrm{m}$ cell strainer. Erythrocytes were lysed using red blood cell lysis buffer (Sigma), and cells were counted and processed for flow cytometry.

Flow cytometry. Equal numbers of cells were stained for each sample, washed with ice-cold PBS, and stained with Zombie Ultraviolet dye (BioLegend) for $10 \mathrm{~min}$ at room temperature. All samples were then blocked with $5 \mu \mathrm{g} / \mathrm{ml}$ aCD16/CD32 (2.4G2; BioLegend) in FACS buffer (PBS containing 2\% FCS and 2 mM EDTA) before staining for specified surface markers at $4{ }^{\circ} \mathrm{C}$ for $25 \mathrm{~min}$. For detection of intracellular molecules, following surface staining, cells were fixed with $1 \%$ paraformaldehyde in PBS for $10 \mathrm{~min}$ at room temperature, permeabilized with the Transcription Factor Staining Kit (eBioscience), and then stained with the antiRELM- $\alpha$ FITC antibody (Peprotech, UK). Samples were acquired using a 5 laser Fortessa with BD FACSDiva software and analyzed with the FlowJo software (v9, Tree Star)

Infection regimes. For high-dose infections, C57BL/6 mice were infected at day 0 with 200 T. muris eggs in a volume of $0.2 \mathrm{ml}$ by oral gavage. For low-dose infections, 20 T. muris eggs were used. Parasite burden in the cecum was assessed at day 21 p.i. and day 35 p.i. At day 21 p.i., MLNCs were removed, a cell suspension was made, and $200 \mu \mathrm{l}$ of $5 \times 10^{6}$ cells $/ \mathrm{ml}$ were restimulated in vitro with $50 \mu \mathrm{g} / \mathrm{ml}$ of whole $\mathrm{E} / \mathrm{S}$, $\mathrm{p} 43$, or $\mathrm{E} / \mathrm{S}^{-\mathrm{p} 43}$. Cell supernatants were taken at $48 \mathrm{~h}$ and pelleted to remove cells. The supernatants were analyzed for cytokine content. At day 35 p.i., mice were exsanguinated by cardiac puncture. The blood was allowed to clot and serum was obtained by centrifuging the blood. Serum was then used for parasitespecific antibody ELISA analysis. Long-term infections were generated by infecting mice with a low-dose infection and terminating the experiment at day 55 p.i. Trickle infections involved a low-dose infection being administered at day $0,2,4,7$, 9 , and 11 p.i. and terminating the experiment at day 35 p.i.

Antibody ELISA. Ninety six-well ELISA plates (Greiner GmbH, Austria) were coated with $5 \mu \mathrm{g} / \mathrm{ml}$ whole $\mathrm{E} / \mathrm{S}$, purified $\mathrm{p} 43$, and $\mathrm{E} / \mathrm{S}^{-\mathrm{p} 43}$, all at $5 \mu \mathrm{g} / \mathrm{ml}$ in sodium carbonate bicarbonate buffer, $\mathrm{pH} 9.6$, and incubated at $4{ }^{\circ} \mathrm{C}$ overnight. The next day, plates were washed with PBS $+0.05 \%$ Tween- 20 five times using an automated ELISA plate washer (Molecular Devices). Plates were incubated with $100 \mu \mathrm{l}$ of 3\% BSA (Sigma) in PBS with Tween-20 for $1 \mathrm{~h}$ and washed as previously described. Fifty microliters of serum from C57BL/6 mice given either 200 (highdose) or 20 (low-dose) T. muris eggs and collected on either day 35 (high dose and post trickle) or day 55 (low dose), was diluted $1 / 80$ in PBS $+0.05 \%$ Tween-20, and plated onto all three antigens. After a 90 -min incubation at room temperature, plates were washed as previously described, and all plates were incubated with goat anti-mouse immunoglobulin (Ig, G, M, and A) conjugated to alkaline phosphatase (A0162, Sigma-Aldrich, UK) at 1/4000 for $60 \mathrm{~min}$. After washing for a final time, plates were developed with $100 \mu \mathrm{l}$ of $p$-nitrophenyl phosphate. The plates were read on a VersaMax ELISA reader and analyzed using SoftMax Pro 6.4.2 software.

In vitro re-stimulation. MLNs were removed from infected C57BL/6 mice at day 21 p.i., and a cell suspension was prepared in RPMI-1640, 10\% FCS, 100IU $/ \mathrm{ml}$ penicillin, $100 \mu \mathrm{g} / \mathrm{ml}$ streptomycin, and $2 \mathrm{mM}$ L-glutamine (all Sigma-Aldrich, UK). The cells were resuspended at $5 \times 10^{6}$ cells $/ \mathrm{ml}$ and plated in 96-well tissue culture plates with $50 \mu \mathrm{g} / \mathrm{ml}$ of $\mathrm{E} / \mathrm{S}, \mathrm{p} 43$, or E/S $\mathrm{S}^{-\mathrm{p} 43}$. After $36 \mathrm{~h}$, cell supernatants were centrifuged at $19,000 \times g$ to pellet cells and supernatants were stored at $-20^{\circ} \mathrm{C}$ until analysis.

Cytokine analysis. Cytokine levels in MLNC supernatants were analyzed by Cytokine Bead Array Flex Sets" for IL-13 (558349) and IFN- $\gamma$ (558296, both from Becton Dickinson). Capture beads conjugated to IL-13 and IFN- $\gamma$ were incubated with supernatants and a dilution range of recombinant murine standards and allowed to mix at room temperature on a rocker for $1 \mathrm{~h}$. Phycoerythrin-conjugated antibodies were added directly onto the supernatants or standards and their capture beads and incubated again for $1 \mathrm{~h}$ on a rocker. The beads were then pelleted by centrifugation, washed, and resuspended with $\mathrm{BD}$ wash buffer. The assay was then read on a MACSquant flow cytometer (Miltenyi) and analyzed using the $\mathrm{BD}$ FACSarray software.

Vaccination protocol. Antigens, $\mathrm{p} 43$ and $\mathrm{E} / \mathrm{S}^{-\mathrm{p}} 43$, were prepared for vaccination by mixing 1:1 with alum (Imject, Thermo Fisher). The antigen was added dropwise to alum and mixed for $30 \mathrm{~min}$. C57BL/6 mice were administered subcutaneously at $50 \mu \mathrm{g}$ per vaccination $(100 \mu \mathrm{l}$ of vaccine) on day -28 and boosted on day -14 . They were then infected with $20 \mathrm{~T}$. muris eggs on day 0 . Mice were culled, blood was taken, and worm burdens were assessed on day 35 p.i. 
Statistical information. All data are shown as the mean \pm SEM or SD when stated. For groups of three or more, a one-way analysis of variance was performed. GraphPad PRISM v.7.0 was used for statistical analysis and a value of $p<0.05$ was considered significant. For qPCR data shown in Supplementary Fig. 1c, Kruskal-Wallis test was performed.

Reporting summary. Further information on research design is available in the Nature Research Reporting Summary linked to this article.

\section{Data availability}

All the data needed to make the conclusions from this study are present in the main paper or supplementary data. Any additional raw data can be obtained by emailing the corresponding authors. "Coordinates and structure factors have been deposited in the Protein Data Bank under accession code 6QIX."

Received: 17 October 2018 Accepted: 12 April 2019

Published online: 28 May 2019

\section{References}

1. Jourdan, P. M., Lamberton, P. H. L., Fenwick, A. \& Addiss, D. G. Soiltransmitted helminth infections. Lancet 391, 252-265 (2018).

2. Cliffe, L. J. \& Grencis, R. K. The Trichuris muris system: a paradigm of resistance and susceptibility to intestinal nematode infection. Adv. Parasitol. 57, 255-307 (2004)

3. Foth, B. J. et al. Whipworm genome and dual-species transcriptome analyses provide molecular insights into an intimate host-parasite interaction. Nat. Genet. 46, 693-700 (2014).

4. Jex, A. R. et al. Genome and transcriptome of the porcine whipworm Trichuris suis. Nat. Genet. 46, 701-706 (2014).

5. Bancroft, A. J., McKenzie, A. N. J. \& Grencis, R. K. A critical role for IL-13 in resistance to intestinal nematode infection. J. Immunol. 160, 3453-3461 (1998).

6. Finkelman, F. D. et al. Interleukin-4- and interleukin-13-mediated host protection against intestinal nematode parasites. Immunol. Rev. 201, 139-155 (2004).

7. Bancroft, A. J., Humphreys, N. E., Worthington, J. J., Yoshida, H. \& Grencis, R. K. WSX-1: a key role in induction of chronic intestinal nematode infection. J. Immunol. 172, 7635-7641 (2004).

8. Hayes, K. S., Bancroft, A. J. \& Grencis, R. K. Immune-mediated regulation of chronic intestinal nematode infection. Immunol. Rev. 201, 75-88 (2004).

9. Albonico, M. et al. Efficacy of mebendazole and levamisole alone or in combination against intestinal nematode infections after repeated targeted mebendazole treatment in Zanzibar. Bull. World Health Organ. 81, 343-352 (2003).

10. Keiser, J. \& Utzinger, J. The drugs we have and the drugs we need against major helminth infections. Adv. Parasit. 73, 197-230 (2010).

11. Cuesta-Astroz, Y., de Oliveira, F. S., Nahum, L. A. \& Oliveira, G. Helminth secretomes reflect different lifestyles and parasitized hosts. Int. J. Parasitol. 47, 529-544 (2017).

12. Eichenberger, R. M. et al. Characterization of Trichuris muris secreted proteins and extracellular vesicles provides new insights into host-parasite communication. J. Extracell. Vesicles 7, https://doi.org/10.1080/ 20013078.2018.1428004 (2018).

13. Julenius, K. NetCGlyc 1.0: prediction of mammalian C-mannosylation sites. Glycobiology 17, 868-876 (2007).

14. Holm, L. \& Laakso, L. M. Dali server update. Nucleic Acids Res. 44 W351-W355 (2016).

15. Konc, J., Cesnik, T., Konc, J. T., Penca, M. \& Janezic, D. ProBiS-database: precalculated binding site similarities and local pairwise alignments of PDB structures. J. Chem. Inf. Model. 52, 604-612 (2012).

16. Tonkin, M. L., Grujic, O., Pearce, M., Crawford, J. \& Boulanger, M. J. Structure of the micronemal protein $2 \mathrm{~A} / \mathrm{I}$ domain from Toxoplasma gondii. Protein Sci. 19, 1985-1990 (2010).

17. Song, G. \& Springer, T. A. Structures of the Toxoplasma gliding motility adhesin. Proc. Natl. Acad. Sci. USA 111, 4862-4867 (2014). (13).

18. Mentink-Kane, M. M. \& Wynn, T. A. Opposing roles for IL-13 and IL-13 receptor alpha 2 in health and disease. Immunol. Rev. 202, 191-202 (2004).

19. Anderson, K. G. et al. Intravascular staining for discrimination of vascular and tissue leukocytes. Nat. Protoc. 9, 209-222 (2014).

20. Cook, P. C. et al. A dominant role for the methyl-CpG-binding protein Mbd2 in controlling Th2 induction by dendritic cells. Nat. Commun. 6, 6920 (2015).

21. Wiesner, D. L., Smith, K. D., Kashem, S. W., Bohjanen, P. R. \& Nielsen, K. Different lymphocyte populations direct dichotomous eosinophil or neutrophil responses to pulmonary cryptococcus infection. J. Immunol. 198, 1627-1637 (2017).
22. Svedberg, F. R. et al. The lung environment controls alveolar macrophage metabolism and responsiveness in type 2 inflammation. Nat. Immunol. 20 571-580 (2019)

23. MacDonald, A. S., Straw, A. D., Bauman, B. \& Pearce, E. J. CD8- dendritic cell activation status plays an integral role in influencing Th2 response development. J. Immunol. 167, 1982-1988 (2001).

24. Johnston, C. J. C. et al. A structurally distinct TGF-beta mimic from an intestinal helminth parasite potently induces regulatory T cells. Nat. Commun. 8, 1741 (2017).

25. Navarro, S. et al. Hookworm recombinant protein promotes regulatory $\mathrm{T}$ cell responses that suppress experimental asthma. Sci. Transl. Med. 8, https://doi. org/10.1126/scitranslmed.aaf8807 (2016).

26. Osbourn, M. et al. HpARI protein secreted by a helminth parasite suppresses interleukin-33. Immunity 47, 739-751 (2017).

27. Kurup, S. et al. Characterization of anti-heparan sulfate phage display antibodies AO4B08 and HS4E4. J. Biol. Chem. 282, 21032-21042 (2007).

28. Radoslavov, G. et al. A novel secretory poly-cysteine and histidine-tailed metalloprotein (Ts-PCHTP) from Trichinella spiralis (Nematoda). PLos ONE 5, https://doi.org/10.1371/journal.pone.0013343 (2010).

29. Wakelin, D. Acquired immunity to Trichuris muris in the albino laboratory mouse. Parasitology 57, 515-524 (1967).

30. Data. Bolt, B. J. et al. Using WormBase ParaSite: An Integrated Platform for Exploring Helminth Genomic Methods Mol. Biol. 1757, 471-491 (2018).

31. Lea, R., Bonev, B., Dubaissi, E., Vize, P. D. \& Papalopulu, N. Multicolor fluorescent in situ mRNA hybridization (FISH) on whole mounts and sections. Methods Mol. Biol. 917, 431-444 (2012).

32. D'Arcy, A., Villard, F. \& Marsh, M. An automated microseed matrix-screening method for protein crystallization. Acta Crystallogr. D 63, 550-554 (2007).

33. Winter, G. xia2: an expert system for macromolecular crystallography data reduction. J. Appl. Crystallogr. 43, 186-190 (2010).

34. Emsley, P., Lohkamp, B., Scott, W. G. \& Cowtan, K. Features and development of Coot. Acta Crystallogr. D 66, 486-501 (2010).

35. Afonine, P. V. et al. Towards automated crystallographic structure refinement with phenix.refine. Acta Crystallogr. D 68, 352-367 (2012).

36. Joosten, R. P., Long, F., Murshudov, G. N. \& Perrakis, A. The PDB REDO server for macromolecular structure model optimization. Iucrj 1, 213-220 (2014).

37. Krissinel, E. \& Henrick, K. Inference of macromolecular assemblies from crystalline state. J. Mol. Biol. 372, 774-797 (2007).

38. Marty, M. T. et al. Bayesian deconvolution of mass and ion mobility spectra: from binary interactions to polydisperse ensembles. Anal. Chem. 87, 4370-4376 (2015)

39. Cain, S. A. et al. Heparan sulfate regulates fibrillin-1 N- and C-terminal interactions. J. Biol. Chem. 283, 27017-27027 (2008).

\section{Acknowledgements}

We would like to thank Professor Eileen Devaney at the University of Glasgow and Professor Mark Blaxter at the University of Edinburgh for initial collaboration on this project. Animal care and welfare were carried out by the staff at the Biological Services Facility (BSF) at the University of Manchester. Tissue samples for immune staining and FISH in Fig. 1b-e and Extended Data Fig. 3a, b were processed using the University of Manchester Histology Core Facility. Advice on stimulation on thioglycolate treatment of mice and the in vitro culture of PECs was given by Dr. Dominik Ruckerl, and advice and antibodies were also provided by Professor Judith Allen and James Parkinson. We would like to thank Professor Anthony Day and Dr. Alex Langford Smith for help and advice with GAG ELISAs in Supplementary Fig. 8 and for providing biotinylated HS used in this figure. Images from Fig. 1b-d and Supplementary Fig. 3a, b and Supplementary Fig. 9a were taken in the Bioimaging core facility at the University of Manchester. The Bioimaging Facility microscopes used in this study were purchased with grants from BBSRC, Wellcome, and the University of Manchester Strategic Fund. We would also like to thank the Bio-MS core facility for the mass spectrometry analysis. We would like to thank Diamond Light Source for access to Beamline i04 (MX12788-12). We would also like to thank Dr. Kevin Couper, Dr. Pawel Paszek, and Dr. Douglas Dyer for helpful discussions on the paper. This work was funded by Wellcome Trust Investigator awards WT100290MA and Z10661/Z/18/Z and A.J.B., T.A.J., K.S.H., S.T., E.D., C.S., D.J.T., and R.K.G. are part of the Wellcome Trust Center for Cell Matrix funded by award Z03128/ $\mathrm{Z} / 16 / \mathrm{Z}$.

\section{Author contributions}

Conceptualization, R.K.G. and A.J.B.; data curation, A.J.B., C.W.L., T.A.J., P.C.C., and B.B.; formal analysis, A.J.B., C.W.L., T.A.J., P.C.C., and B.B.; funding acquisition, R.K.G; investigation, A.J.B., C.W.L., T.A.J., K.S.H., S.T., E.D., C.S., S.B., A.M., E.A.M., M.D.B., B.B, and A.P.F.; methodology, C.W.L. and E.A.M.; project administration, R.K.G., A.J.B., and D.J.T.; resources, R.K.G., C.W.L., T.A.J., E.A.M., D.J.T., A.M., A.Mac; supervision, R.K.G., A.J.B., C.W.L., and E.A.M.; validation, A.J.B., K.S.H., C.W.L., E.A.M., A.M., S.L. B., C.S., E.D., P.C.C., and T.A.J.; visualization, A.J.B., K.S.H., S.L.B., and S.T.; writing of the original draft, A.J.B. and R.K.G.; writing-review and editing, R.K.G., A.J.B., C.W.L., T.A.J., and D.J.T. 


\section{Additional information}

Supplementary Information accompanies this paper at https://doi.org/10.1038/s41467019-09996-z.

Competing interests: The authors declare no competing interests.

Reprints and permission information is available online at http://npg.nature.com/ reprintsandpermissions/

Journal peer review information: Nature Communications thanks Malcolm Kennedy and other anonymous reviewer(s) for their contribution to the peer review of this work.

Publisher's note: Springer Nature remains neutral with regard to jurisdictional claims in published maps and institutional affiliations. (c) (i) Open Access This article is licensed under a Creative Commons Attribution 4.0 International License, which permits use, sharing, adaptation, distribution and reproduction in any medium or format, as long as you give appropriate credit to the original author(s) and the source, provide a link to the Creative Commons license, and indicate if changes were made. The images or other third party material in this article are included in the article's Creative Commons license, unless indicated otherwise in a credit line to the material. If material is not included in the article's Creative Commons license and your intended use is not permitted by statutory regulation or exceeds the permitted use, you will need to obtain permission directly from the copyright holder. To view a copy of this license, visit http://creativecommons.org/ licenses/by/4.0/.

(C) The Author(s) 2019 